1 Universidade Federal de Minas Gerais (UFMG), Núcleo de Educação em Saúde Coletiva (Nescon) - Belo Horizonte (MG),

Brasil.

Orcid: https://orcid

org/0000-0002-1673-

1794

gel_mor@yahoo.com.br

2 Universidade Federal de Minas Gerais (UFMG),

Núcleo de Educação em Saúde Coletiva (Nescon)

- Belo Horizonte (MG),

Brasil.

Orcid: https://orcid. org/0000-0002-42384394

giselesaporetti@yahoo.

com.br

3 Universidade Federal de Minas Gerais (UFMG),

Faculdade de Medicina,

Departamento de

Medicina Preventiva

e Social (MPS) - Belo

Horizonte (MG), Brasil.

Orcid: https://orcid.

org/0000-0003-1635-

5175

heliannunes@gmail.com

4 Universidade Federal de Ouro Preto (Ufop),

Departamento de

Estatística (DEEST) - Ouro

Preto (MG), Brasil.

Orcid: https://orcid.

org/0000-0002-9060-

0477

tavares@ufop.edu.br

5 Universidade Federal de

Minas Gerais (UFMG)

Faculdade de Medicina,

Departamento de

Medicina Preventiva

e Social (MPS) - Belo

Horizonte (MG), Brasil.

Orcid: https://orcid.

org/0000-0002-1287-

6304

tarcisiommp@gmail.com

\section{Percepções dos adolescentes sobre a violência em um assentamento rural: uma análise qualitativa}

\author{
Adolescents' perceptions of violence in a rural settlement: a \\ qualitative analysis
}

Angela Moreira1, Gisele Marcolino Saporetti2 , Helian Nunes de Oliveira ${ }^{\mathbf{3}}$, Ricardo Tavares ${ }^{\mathbf{4}}$ Tarcísio Márcio Magalhães Pinheiro 5

DOI: 10.1590/0103-11042018S407

RESUMO O objetivo deste artigo foi analisar as percepções de adolescentes de uma escola localizada em um assentamento rural, no município de Alto Paraíso de Goiás, em relação à violência. Realizou-se estudo qualitativo, utilizando-se entrevistas semiestruturadas. A sistematização e a interpretação dos dados foram realizadas pela análise de conteúdo definida por Bardin. Os adolescentes pesquisados relataram variadas formas de violência, por diversas causas, exercidas por diferentes atores, em diversos locais e acometendo todas as faixas etárias. Conclui-se que a escola e a família são fontes privilegiadas de mediações de conflitos, possibilitando uma atuação ampla no campo da prevenção da violência.

PALAVRAS-CHAVE Percepção. Adolescente. Violência. Escola. Assentamentos rurais.

ABSTRACT The aim of this article was to analyse the perceptions of the adolescents, in a school located in a rural settlement, in the municipality of Alto Paraiso de Goiás, regarding violence. A qualitative study was carried out, using a semi-structured interview. The systematization and interpretation of the data were performed by the content analysis defined by Bardin. The adolescents surveyed identified several forms of violence, carried out by different actors, in different places, that affects all age groups, and has several causes. It is concluded that school and family are privileged sources of conflict mediation, making possible a broad action in the field of violence prevention.

KEYWORDS Perception. Adolescent. Violence. School. Rural settlements. 


\section{Introdução}

A violência é um fenômeno social que exige políticas públicas para o seu enfrentamento. É considerada uma das grandes causas de mortalidade no mundo. $\mathrm{O}$ aumento mundial de casos de violência em indivíduos de todas as idades e sexos foi um fator contributivo para a evolução do próprio conceito de violência'.

A Organização Pan-Americana da Saúde entende que a violência é um acontecimento sócio-histórico que acompanha as experiências e as relações humanas. Destaca que ela é uma questão de saúde pública, que afeta o indivíduo e a coletividade, e que exige a articulação de políticas públicas e a organização de serviços específicos que desenvolvam ações de cuidados para a sua prevenção, tratamento e vigilância ${ }^{2}$.

Para Minayo $^{3}$, a violência é um fenômeno social e de saúde pública que tem chamado a atenção de especialistas, teóricos e do próprio poder público.

A Organização Mundial da Saúde (OMS), no Relatório Mundial sobre Violência e Saúde, conceitua a violência como

o uso intencional da força física ou do poder, real ou em ameaça, contra si próprio, contra outra pessoa, ou contra um grupo ou uma comunidade, que resulte ou tenha grande possibilidade de resultar em lesão, morte, dano psicológico, deficiência de desenvolvimento ou privação4(5).

Dados epidemiológicos comprovam que a violência afeta de forma direta e indireta a saúde da população mundial, causando aumento do número de mortes por homicídios e suicídios. Segundo a OMS', registram-se anualmente, no mundo, mais de 1,3 milhão de mortes em consequência da violência, em todas as suas formas - autodirecionada, interpessoal e coletiva -, o que corresponde a $2,5 \%$ da mortalidade geral.

A violência autoinfligida engloba os casos relacionados com suicídios (suicídio, ideação suicida e tentativas de suicídio) e com autoabusos (agressões a si próprio e as automutilações); a violência interpessoal contempla a violência da família e do parceiro íntimo (agressões contra crianças, mulher ou homem e idosos); a violência comunitária ocorre na esfera social, entre conhecidos e desconhecidos, por meio de agressões físicas, estupros, entre outras; e a violência coletiva sucede nos círculos sociais, políticos e econômicos e caracteriza a dominação de grupos e do Estado. O Ministério da Saúde acrescenta aos tipos de violência: a violência estrutural, que se refere aos processos sociais, políticos e econômicos que reproduzem e perpetuam a fome, a miséria e as desigualdades sociais; a violência de gênero e a de etnia.

Além das formas, as ações de violência são categorizadas de acordo com a sua natureza, que pode ser de ordem física, psicológica, sexual e as que dizem respeito ao abandono, negligência ou privação de cuidados $\mathbf{2}^{\mathbf{2} 4}$.

Especificamente em relação aos adolescentes, a violência configura-se como um grande desafio de saúde pública no Brasil. As mortes de crianças e adolescentes por causas externas - acidentes e homicídios - têm aumentado nas últimas décadas: em 1980, representavam 6,7\% do total de óbitos na faixa de 0 a 19 anos de idade, em 2013, a participação elevou-se para 29\%. Entre 1980 e 2012, morreram, no País, 880.386 pessoas devido a disparos de armas de fogo, sendo que, dessas vítimas, 497.570 (56,6\%) eram jovens na faixa de 15 a 29 anos de idade 5 .

O Relatório das Nações Unidas sobre a Violência contra Adolescentes ${ }^{6}$ afirma que a violência contra adolescentes está presente em todos os países, em diversas culturas, classes sociais, níveis de escolaridade, faixas de renda e origens étnicas.

O Ministério da Saúde, no documento 'Impacto da violência na saúde dos adolescentes', evidencia que a violência pode gerar problemas de diversas ordens, como sociais, emocionais, psicológicos e cognitivos durante toda a vida, podendo levar a outros prejuízos comportamentais à saúde ${ }^{2}$.

Dessa forma, este artigo tem por objetivo 
descrever e analisar as percepções de adolescentes residentes em um assentamento rural em relação à violência e as possibilidades de seu enfrentamento.

\section{Métodos}

Trata-se de estudo qualitativo descritivo. Os dados foram coletados por meio de entrevista semiestruturada, com adolescentes de 10 a 19 anos, de uma escola rural filantrópica de direito privado, localizada no Assentamento Sílvio Rodrigues (ASR) no município de Alto Paraíso de Goiás, em Goiás. O ASR, onde residem 119 famílias totalizando 449 pessoas, foi criado pelo Instituto Nacional de Colonização e Reforma Agrária (Incra) em 2004.

Foi realizada uma amostragem intencional não probabilística e por saturação. $\mathrm{O}$ estudo contou com a participação de 19 adolescentes. Foram elegíveis aqueles que aceitaram participar da pesquisa e que assinaram o Termo de Consentimento Livre e Esclarecido (TCLE), juntamente com os pais ou responsáveis; bem como o Termo de Assentimento, que foi assinado pelos participantes após todos os esclarecimentos sobre os objetivos do estudo e dos procedimentos de pesquisa. A coleta foi realizada em de dezembro de 2016, por meio de entrevistas individuais, gravadas, em uma sala privada na escola. Foi assegurado o anonimato dos alunos participantes das entrevistas.

As entrevistas foram conduzidas pelas seguintes questões norteadoras: 1 . O que você entende por violência? 2. Por que existe violência? 3. Existe violência onde você mora? Quais os tipos mais frequentes? 4. A violência incomoda você? Qual o tipo de violência que mais o incomoda? 5 . Você já sofreu algum tipo de violência? Qual? Como foi? 6. A violência já o impediu de fazer alguma coisa? 7. Você já praticou alguma violência? Descreva. 8. Você acha que é possível vencer a violência? Como? e 9. Gostaria de acrescentar algo mais?.

Para a análise dos dados, utilizou-se a técnica de Análise de Conteúdo proposta por Bardin? 7 .
Este artigo é resultado da dissertação de mestrado intitulada 'Percepções dos adolescentes sobre a violência em um assentamento rural', apresentada ao Programa de Pós-Graduação em Promoção da Saúde e Prevenção da Violência da Faculdade de Medicina da Universidade Federal de Minas Gerais (UFMG). A pesquisa foi aprovada pelo Comitê de Ética em Pesquisa da Universidade Federal de Minas Gerais, no dia 21 de novembro de 2016, com emissão do parecer $\mathrm{n}^{0}$ 61529516.0.00005149.

\section{Resultados e discussão}

Participaram 19 adolescentes, sendo 8 do sexo masculino e 11 do sexo feminino, com idade entre 10 e 19 anos. Todos eram alunos regularmente matriculados e frequentes do $4^{\circ}$ ano do ensino fundamental ao $3^{\circ}$ ano do ensino médio.

Os relatos dos adolescentes foram categorizados segundo seus entendimentos sobre: percepções sobre a violência, violência no ASR (tipos frequentes, tipos de violência que mais incomodam, tipos de violência sofridas, violência praticada) e possibilidades de enfrentamento e superação.

\section{Percepções sobre a violência}

Para os entrevistados, a violência é entendida como uma forma de agredir, ofender, bater e xingar alguém. Pode ocorrer na rua, na escola e em casa, ser exercida por familiares - pai, padrasto, mãe -, por pessoas mais velhas e que se julgam mais fortes. Ainda segundo os entrevistados, os atos de violência podem acontecer em função do desagrado de alguém com a cor da pele do outro, da ingestão de bebida alcoólica por parte de quem pratica a violência e pela ausência de diálogo. Também consideram violência maltratar os animais e as plantas.

Quando alguém agride uma pessoa, xinga ela, xinga pela cor dela. (E5). 
A violência [...] geralmente acontece muito nas famílias, o pai espancar a filha por ela ter saído ou o padrasto pegar uma filha que nem é dele, entendeu? Em relação a isso, a mãe também beber e bater nos filhos. E também existe a violência nas ruas que um maior de idade vai lá e pega, é considerado pra ele pirralho, aí ele agride. Também tem nas escolas pessoas que se acham superior às outras, os mais fortes, aí eles querem sempre partir pra violência, nunca pra conversa, eles acabam batendo. É isso para mim. (E14).

Violência não é só com ser humano, com animal, com as plantas, com tudo que a gente faz de ruim com qualquer coisa, com qualquer pessoa e animal é violência. (E8).

A violência, de acordo com os adolescentes escolares pesquisados por Brandão Neto, Silva, Aquimo et al. ${ }^{8}$, é vivenciada de forma constante e em diversos ambientes: familiar, escolar, vizinhança e nas áreas de lazer da comunidade. Nessa mesma pesquisa, foi identificada a violência ecológica como um fator de preocupação com o processo de adoecimento e meio ambiente.

Os adolescentes escolares da região do Recanto das Emas, em Brasília (DF), pesquisados por Ribeiro ${ }^{9}$, relataram que vivenciaram violência em diferentes locais: escola, família e comunidade; e que foram praticadas por: outros alunos, professores e pais.

Estudos com adolescentes demonstram que a definição que apresentam da violência está bastante relacionada com a agressão física ${ }^{10}$. Os adolescentes de uma escola estadual no município Senhor do Bonfim (BA), pesquisados por Paixão, Santos, Matos et al.11, compreenderam como violência somente aquela relacionada com a dimensão física, não identificaram as dimensões psicológica, moral e institucional como tal.

Na pesquisa realizada por Brandão Neto, Silva, Aquimo et al. ${ }^{\mathbf{8}}$, os adolescentes escolares pesquisados apontaram haver relação entre a violência e o consumo de drogas, as condições sanitárias e socioambientais.

Os entrevistados do presente estudo acreditam que a violência pode ser verbal, física, sexual e psicológica. Para eles, a violência representa a perda da razão, que não há aspecto positivo na violência e que prejudica ambas as partes - a vítima e o agressor.

[...] pra mim violência é uma coisa ruim que as pessoas usam para intimidar as outras pessoas, tanto de forma verbal, física, emocional, que não tem nenhum lado positivo. Pra mim só tem lado negativo, isso prejudica ambas partes. (E11).

[...] Eu acho que violência é quando as pessoas começam a disputar por alguma coisa e perdem a razão. Acredito que violência ela é tanto verbal, como agressão física, então, psicológica também. (E12).

Tem violência de vários tipos, tanto sexual, como violência de palavras, tem agressão física. Para mim violência é isso. (E15).

Silva, Lunardi, Lunardi et al.12, ao pesquisarem o perfil epidemiológico da violência contra crianças e adolescentes em um Centro de Referência Especializado em Assistência Social, identificaram o predomínio do abuso sexual, seguido das violências física e psicológica.

A existência da violência, segundo os entrevistados da atual pesquisa, deve-se ao preconceito - de raça, cor e gosto -, à falta de respeito ao semelhante, à indiferença e não aceitação da opinião alheia e à intolerância. A ausência de educação e a falta de regras na sociedade também foram mencionadas.

Preconceito de cor, raça, de gostos. (E9).

Acho que é pela indiferença, por não aceitar a opinião do próximo, entendeu, [...] é por falta de respeito aos seus semelhantes. (E11).

Porque existe intolerância das pessoas a tudo que não concorda. (E17).

Porque quase ninguém tem educação. (E5). 
Porque eu acho que a sociedade não impõe tantas regras para a violência acabar. Aí eu acho que eles meio que não se importa com essa violência. (E8).

Entre as causas da violência elencadas pelos adolescentes pesquisados por Santana ${ }^{10}$, estão: problemas familiares, discriminação, más amizades e falta de cuidado por parte dos pais.

Maia, Araujo e Santos Junior ${ }^{\mathbf{1 3}}$ verificaram que a dificuldade dos adolescentes em aceitar as características físicas dos demais, bem como a idade, o gênero, as características emocionais e de personalidade, colabora para a ocorrência de violências físicas e psicológicas entre eles no ambiente escolar.

Os adolescentes escolares pesquisados por Brandão Neto, Silva, Aquino et al. ${ }^{8}$ relacionaram a ocorrência de violência a diversos fatores, entre eles: a discriminação, o preconceito, a indiferença, a humilhação, a exclusão social e o não acesso às políticas públicas.

Por fim, um dos entrevistados neste estudo acredita que a existência da violência está relacionada com uma questão cultural que remete aos tempos da escravidão, quando os brancos podiam agredir os negros por não obedecerem. Outros alunos identificam que a violência pode ser vivida no ambiente doméstico como algo do cotidiano entre os pais e dos pais com os filhos; assim, há a possibilidade de a vítima reproduzir esse comportamento no trabalho, na escola e na constituição de uma nova família, gerando um ciclo de violência. Também se registrou a opinião de que a violência existe porque está evidenciada no mundo e na televisão.

Eu acho que isso veio bem dos tempos atrás, as pessoas, por serem brancas, eles rejeitavam as pessoas negras, então isso aconteceu nas guerras de antigamente e foi levando, existia os escravos e aí eles pegaram e tiveram essa lei de bater naqueles que não queriam obedecer. (E14).

Eu acho que violência é uma questão de cultura, tipo assim uma coisa que já vem de família, se minha família é do tipo, se eu sou um filho que eu vou ver meu pai bater na minha mãe todo dia, discussão e xingamento e guerra, esses trens, tudo na minha casa, eu vou ser uma pessoa que, na vida, na escola, no trabalho, em qualquer lugar, vai ser uma pessoa violenta. E assim também gerando, se meus pais são violentos, eu vou ser violento com a minha futura esposa, meus filhos vão seguir o mesmo exemplo, vai achar a coisa normal, cultural, né?! (E12).

[...] essa violência existe porque o povo tá querendo fazer, é o mundo que faz, não é a gente. $A$ gente tá vendo a televisão, tá acontecendo uma coisa e a gente vê e a gente fazer não é coisa boa também, né? (E10).

Para autores como Silva, Coelho, Caponi14 e Ralo ${ }^{\mathbf{1 5}}$, um ambiente familiar em que a violência psicológica está presente entre os pais e é presenciada pelos filhos pode colaborar para que os filhos reproduzam esse tipo de violência com colegas na escola, com familiares e até mesmo na família que mais tarde constituirão.

Rates, Melo, Mascarenhas et al. ${ }^{16}$ identificaram o ambiente doméstico como um local mais suscetível de acontecer violência entre as pessoas.

Da mesma forma, Borges e Alencar ${ }^{17}$ afirmam que a presença da violência familiar, escolar e social na vida dos adolescentes desde muito cedo colabora para que os adolescentes a internalizem e passem a reproduzi-la.

Para Silva, Lunardi, Lunardi et al.12(427)

muitos pais, ainda, consideram o uso da violência como medida disciplinadora e educativa, constituindo-se, possivelmente, na reprodução de práticas adotadas por seus pais e das quais já foram vítimas em sua infância e adolescência.

É importante considerar que, nos relatos dos pesquisados, as considerações referentes às desigualdades sociais advindas e constituídas a partir da condição da classe social não apareceram atreladas ao conceito ou às percepções sobre a violência. 


\section{Violência no Assentamento: tipos frequentes}

Muitos dos entrevistados afirmam que não existe ou que nunca viram violência onde residem. Relatam que no município de Alto Paraíso de Goiás, referindo-se à parte urbana, há brigas na praça, roubos e mortes.

Não, nunca vi. (E1).

Só em Alto Paraíso que vi. Uns caras batendo nos outros, brigando na pracinha. Lá tem muita gente que briga, e tem muitas violência, uns machucando os outros, batendo nos outros e vai para cadeia. (E2).

De acordo com Gessner, Fonseca e Oliveira ${ }^{18(109)}$, o conceito de violência para os adolescentes pode ser

entendido como algo muito maior ou mais grave e diferente do que acontece comumente no seu cotidiano. Daí decorre a dificuldade de se perceber como vítima e reconhecer as relações violentas em que está inserido.

A maior parte dos adolescentes pesquisados por Ralo ${ }^{15}$ não percebeu a violência a sua volta.

Os entrevistados que afirmam haver violência verbal e física na escola, por meio de xingamentos relacionados com características físicas, falar mal, mesmo sem conhecer a pessoa, e agressões físicas e intimidação destacam o bullying por orientação sexual. Ademais, relatam violência em festas e bares, tanto física quanto verbal. Identificam também que algumas das ações de violência estão associadas ao uso de drogas e álcool.

É, existe. bullying por pessoa que escolheu gostar de outro gênero. (E17).

Sim. Porrada, ficar xingando um a outro, que eu tô lembrado, só. (E16).

De intimidação, que é mais frequente nas escolas e física, na região mesmo, que é mais em barzinho, essas coisas que tem aqui. (E11).

[...] quando a gente vai pra festa tem muita violência, as pessoas briga, tanto em discussão quanto entra em porrada também. É porque eles usa droga, álcool e aí acaba afetando, eles acabam fazendo violência. (E8).

Moura, Cruz, Quevedo ${ }^{19}$ verificaram maior prevalência de bullying verbal, ao detectarem o uso de apelidos pejorativos evidenciando determinada característica física ou fragilidade da vítima, entre adolescentes escolares.

Ribeiro9, ao investigar adolescentes escolares da região do Recanto das Emas, em Brasília (DF), verificou a predominância da violência física, seguida da psicológica e, por último, a sexual.

Maia, Araújo e Júnior ${ }^{13}$ reforçam a presença da violência entre adolescentes na escola. Para os autores, a violência é algo do cotidiano dos adolescentes, podendo iniciar com a violência psicológica, por meio de xingamentos e provocações verbais, evoluindo para a violência física.

Rates, Melo, Mascarenhas et al. ${ }^{16}$, ao analisarem as notificações das violências contra crianças, verificaram que o consumo de álcool foi significativo entre os agressores.

A intolerância quanto às características físicas, comportamentais e cognitivas são fatores que podem levar a atitudes de violência entre adolescentes nas escolas ${ }^{\mathbf{1 3}}$.

Os pesquisados relataram ainda ter conhecimento de agressão física entre cônjuges e de assédio sexual:

Assim, poucas, não tão faladas, mas poucas. Geralmente maridos que batem nas mulheres, maridos bêbados, assim, já existiu, já ouvi falar de mulher bater no marido, assim bem poucas mesmo. (E14).

Sim. A verbal. É mais em questão de xingamento e também eu acho que você está passando na rua e a pessoa mexe com você, eu acho que isso é violência. (E18). 
Para Soares e Lopes ${ }^{\mathbf{2 0}}$, a violência entre cônjuges é fator presente em assentamentos rurais. Identificaram haver violência por parte dos companheiros contra mulheres jovens e detectaram a vulnerabilidade, falta de oportunidade e alternativas vividas por elas.

A violência sexual identificada pelos adolescentes escolares da região do Recanto das Emas, em Brasília (DF), era em maioria praticada por adultos do sexo masculino; e o toque no corpo ou nos seios foi relatado como predominante 9 .

\section{Tipos de violência que mais incomodam}

Todos os entrevistados disseram se incomodar com a violência. Alguns se sentem inseguros, abalados emocionalmente com o sofrimento das pessoas e ficam com "coração acelerado", sentem-se desejosos de ajudar quem sofre.

Porque tem umas vezes que eu vejo as pessoas brigando e aí eu começo a ficar com o coração batendo demais. (E2).

Fico (incomodado), porque vejo muitas pessoas sofrendo. (E3).

Incomoda, deixa eu querendo ajudar. (E4).

De acordo com Ralo15, os adolescentes também relatam sentimentos provocados pela violência. A autora afirma ainda que a autoestima é prejudicada com a violência.

Entre os tipos de violência que mais incomodam, estão: violência física (com mulheres: matar e bater; com crianças: pegar, bater, matar, agredir, levar para longe dos pais; e em geral: brigar e matar); violência verbal (xingamentos); violência psicológica (intimidação); e violência sexual (com menor de idade, especificamente menina).

Matar as mulheres. (E1).

Incomoda bater em mulher, injustiça. (E9).
[...] é as pessoas que pegam as crianças, bate, mata. Por causa que assim: as crianças é inocente, e vem sendo agredida por homem. É muito ruim ver as pessoas sofrer por causa, porque está andando e chega a pessoa vai, bate, espanca, machuca, carrega, fica longe dos pais. (E3).

Todas me incomodam, mas as duas que me incomoda mais é a intimidação, porque isso tira a autoestima da pessoa, enfraquece, e a física também, que é prejudicial. (E11).

É a de maus tratos de menores. E também violência (sexual) com menor de idade, menina. (E10).

[...] a violência sexual incomoda bastante, deve ser muito dolorosa pras pessoas, mas você não sabe o que se passa na cabeça da pessoa. (E18).

Os adolescentes escolares investigados por Brandão Neto, Silva, Aquino et al. ${ }^{\mathbf{8 ( 6 )}}$ também relataram incômodo em relação à violência:

eles não demonstraram aceitar os fatos, assumindo uma atitude de repúdio e de inquietação contra esta realidade, que priva as pessoas do direito de exercer sua cidadania.

\section{Tipos de violências sofridas}

A maior parte dos entrevistados disse não ter sofrido algum tipo de violência; e, entre estes relatos, há um que não reconhece a violência verbal como um tipo de violência.

Não, nunca. (E6).

Não, graças a Deus. (E10).

Nunca. Xingar sim, agora violência física, não. (E16).

Ralo ${ }^{15(107)}$ identificou que adolescentes que sofreram violência doméstica "não se reconheceram como vítimas potenciais de 
violência, mesmo tendo sido submetidos a ela no contexto doméstico". Para a autora, é possível também que os adolescentes omitam que sofreram algum tipo de violência doméstica em função do estigma e preconceito relacionados. Cogita também a possibilidade de a violência doméstica ser invisível no lar, por estar atrelada à ideia de educação e disciplina.

Os demais entrevistados relataram já ter sofrido algum tipo de violência em casa, na escola e na rua. Foram citadas situações de preconceito e bullying em função da cor e características pessoais, ameaça em briga, sentimento de exclusão em atividade escolar, assédio sexual por homens na rua, abuso sexual por padrasto e agressão por parte dos pais.

Alguém já me chamou de negro, preto, aqui na escola. (E5).

Tipo verbal, a pessoa me xinga de gorda, me ameaça, também já fui ameaçada. (E8).

No evento que teve aqui na escola, que não colocaram a gente. Não incluíram a gente. Falaram que era só escolhidos da escola, os melhores, aí não incluíram a gente, aí nós ficou ofendido [...]. (E9).

Eu tenho um padrasto, já há muito tempo que ele mora com minha mãe, há 11 anos, então, assim, eu comecei a sofrer quando eu fui entrando com 9 anos, eu saía de casa para não ser agredida mas isso acontecia porque ele bebia, e ele queria tipo assim abusar e geralmente eu não queria, era criança, fui entendendo isso com uns 12 anos, então, assim, eu também não aceitava, então eu acho que ele ficava mais ainda irritado e queria me bater, por isso eu tenho várias manchas no corpo, por causa dessas coisas, já apanhei de fio, vara, chinelo, várias outras coisas. (E14).

Malta, Mascarenhas, Bernal et al. 21, ao analisarem dados do Inquérito da Vigilância de Violências e Acidentes (Inquérito Viva 2009) quanto à ocorrência de causas externas em adolescentes de 10 a 19 anos, identificaram que os locais onde são mais frequentes acidentes e violência com adolescentes são, em primeiro lugar, a rua, seguida do domicílio e, posteriormente, da escola - o que sugere pensar em ações de promoção da saúde que envolvam esses locais.

Paixão, Santos, Matos et al."1, em estudo sobre a percepção de adolescentes, em escolas públicas estaduais do município de Senhor do Bonfim (BA), a respeito da violência, identificaram que os adolescentes pesquisados vivenciaram, no ambiente escolar, tipos diversos de violência: física, moral e psicológica, esta última tanto por parte de alunos como de professores.

Segundo Ribeiro ${ }^{9}$, as agressões psicológicas sofridas por adolescentes na escola, tais como xingamentos e constrangimentos, são praticadas por outros alunos, por professores e até pela direção da escola.

A violência sexual vivenciada pelas adolescentes pesquisadas por Siqueira, Arpini, Savegnago 22 é perpetrada principalmente por pais biológicos ou padrastos, no ambiente doméstico.

\section{Violência praticada}

Alguns participantes relataram já ter praticado violência. Entre os atos de violência praticados, estão: bater em menores e em colegas, empurrar, brigar, xingar, ameaçar, apelidar e zoar.

Já fiz isso uma vez na escola, fiquei irritada com uma aluna e apenas empurrei ela, mas assim rolou uma desculpa de nós duas. (E14).

Eu acho que já sim, na forma de colocar apelido, de intimidar também eu devo ter feito algumas vezes. (E11).

Fui zoar um garoto, ele também, aí eu parti para cima e acabou gerando isso [briga]. (E12).

Os adolescentes escolares pesquisados por Ralo ${ }^{15}$ também relataram ter praticado violência. Utilizaram da violência para justificar violência e como forma de resolver conflito. Agrediram amigos, colegas, desconhecidos, vizinhos e ex-namorados. 


\section{Possibilidades de enfrentamento e superação}

A maioria dos entrevistados acha possível vencer a violência e apresenta diferentes ações para isso, com destaque para a necessidade de conscientização por meio de palestras, eventos, encontros e a importância do diálogo. Ressaltam que a conscientização e o diálogo a respeito da violência devem iniciar na infância e adolescência e ser tratados amplamente na escola.

Acho que sim. Primeiro pra mim é a questão do princípio, que pra mim é a questão do respeito, a pessoa tem que aprender a respeitar a opinião dos outros e saber lidar com a diferença. Eu acho que uma forma de conscientização, palestras, eventos, encontros isso pode ajudar a influenciar. (E11).

Eu acho que tem de tratar de uma forma mais geral a violência na escola, sabe, com as crianças, com os adolescentes, porque isso influencia muito. $\mathrm{Na}$ nossa vida a gente passa mais tempo na escola, eu acho que isso tem que ser tratado. (E11).

Os adolescentes investigados por Pinto, Araújo, Carvalho et al. ${ }^{23}$ disseram que a escola deve conscientizar os alunos a respeito da violência, abordar o tema e esclarecer quanto às consequências para ajudar a suprir a falta de informação.

$\mathrm{Melo}^{24}$ ressalta que a raiz do problema da violência está na dificuldade em estabelecer os processos de comunicação e que se faz necessário aproveitar as possibilidades de interação que a fala pode propiciar. Ainda para a autora, os projetos que abordam a violência devem buscar estratégias metodológicas para estimular o diálogo. Dentre as experiências de prevenção de violência, destacam-se atividades que buscam a organização de grupos, parcerias, redes, debates públicos,

desenvolvimento e formação de valores que preconizam a não-violência e o respeito pelo outro, em determinados espaços sociais, por meio de mecanismos gerais, voltados para todos os atores aí incluídos, por exemplo, todos os alunos de uma escola, todos os integrantes de uma associação, [bem como o] desenvolvimento de projetos, programas e políticas, destinados às escolas, famílias, comunidades, organizações sociais; pela pactuação de normas de convívio e desenvolvimento de atitudes cooperativas e solidárias nos mais diferentes espaços sociais ${ }^{24(16)}$.

Segundo uma parte dos entrevistados pelo presente estudo, fazer amizades, ter mais união e paciência, cada um fazer a sua parte, pensar e refletir no que faz, conversar para entender os motivos de quem agride podem ser formas de prevenção da violência. Além disso, identificam a necessidade de haver mais regras na sociedade:

Fazendo amizade uns com os outros e nunca brigar na vida deles. (E2).

Olhar a vida de outra maneira, unir mais, ter mais paciência, conversar com quem fez a agressão para entender os motivos. (E17).

Eu acho que sim, se a sociedade imposse mais regras, se a sociedade fosse mais rígida, eu acho que sim. (E8).

Uma das estratégias para prevenir a violência, proposta por Melo, Melo, Pimenta et al. ${ }^{25(96)}$, é a

a criação de espaços de participação que coloquem os adolescentes uns em contatos com os outros e assim se recomece o longo aprendizado da solidariedade e da recriação de laços de sociabilidade.

\section{Considerações finais}

Os resultados indicaram que os adolescentes identificaram que a violência tem grande abrangência, podendo ser física, verbal, sexual 
e psicológica. Apontaram que as manifestações de violência podem ocorrem em diversos locais, tais como escola, rua, casa, festas; e podem ser exercidas por diferentes pessoas, familiares, desconhecidos e colegas. Sofrem a violência todas as faixas etárias, em virtude do preconceito racial, sexual e social, da falta de respeito, da indiferença, da intolerância, da ausência de educação e da falta de regras na sociedade.

A violência física contra mulheres e crianças, a violência verbal, a violência psicológica e a violência sexual, especialmente contra menores de idade e meninas, estão entre os tipos de violência que mais incomodam os pesquisados.

Dentre as violências sofridas, destacaram o assédio sexual na rua e por homens, o abuso sexual por padrasto, a agressão por parte dos pais, a exclusão em atividade escolar e o bullying em função da cor e de características pessoais. Apontaram as violências física, verbal e psicológica como sendo as que eles praticaram. Entre elas, estão: matar animais, bater, empurrar, brigar, xingar, ameaçar, apelidar e zoar.

A maioria dos entrevistados evidenciou que a violência pode ser vencida e elencou ações para que os diferentes atores pudessem contribuir para a prevenção da violência. Dentre as ações individuais, destacam-se necessidade de ter mais amizades, união, paciência, reflexão, diálogo e vontade de não praticar violência. Identificaram a necessidade de maior conscientização por parte da escola a respeito da violência por meio de palestras e eventos e que a abordagem seja realizada desde a infância. Indicaram a necessidade de haver leis mais rígidas e maior ação policial no combate à violência.

Com os resultados obtidos nesta pesquisa, é importante destacar a carência de estudos acerca do tema violência e adolescentes em assentamentos rurais, ficando evidente a necessidade de mais estudos e pesquisas aprofundadas sobre o tema.

\section{Colaboradores}

Moreira A contribuiu significativamente para a elaboração do rascunho e revisão crítica do conteúdo. Saporetti GM contribuiu substancialmente para a concepção, planejamento, análise e interpretação dos dados. Oliveira HN contribuiu para o planejamento, interpretação e revisão final do artigo. Tavares $\mathrm{R}$ contribui para as análises estatísticas e revisão do manuscrito. Pinheiro TMM contribuiu para a concepção e delineamento do estudo, análise crítica e aprovação final do artigo. 


\section{Referências}

1. Organização Mundial de Saúde. Relatório Mundial Sobre a Prevenção da Violência 2014. Núcleo de Estudos da Violência da Universidade de São Paulo, 2015.

2. Brasil. Ministério da Saúde. Impacto da violência na saúde das crianças e adolescentes. Prevenção de violências e promoção da cultura de paz. Brasília, DF: Ministério da Saúde, 2009 [acesso em 2016 mar 14]. Disponível em: http://bvsms.saude.gov.br/bvs/publicacoes/impacto_violencia.pdf.

3. Minayo MCS. Violência e Saúde [internet]. Rio de Janeiro: Fiocruz; 2006 [acesso em 2017 fev 1]. Disponível em: https://books.google.com.br/books?hl=pt BR\&lr=\&id=Rxb0AgAAQBAJ\&oi=fnd $\& p g=$ PA7\&dq $=$ viol\%C3\%AAncia+e+sa\%C3\%BAde+minayo+2006\& ots=Y9tm5KTMVe\&sig=cyRphncZbbNji030YTw49 ncMK7s\#v=onepage \&q=viol\%C3\%AAncia\%20e\%20 sa\%C3\%BAde\%20minayo\%202006\&f=false.

4. Krug EG, Dahlberg LL, Mercy JA, et. al. Relatório Mundial sobre violência e saúde [internet]. Genebra: OMS; 2002 [acesso em 2017 fev 11]. Disponível em: http://www.opas.org.br/wp-content/uploads/2015/09/relatorio-mundial-violencia-saude.pdf.

5. Waiselfisz JJ. Mapa da violência 2015: Mapa da Violência: Adolescentes de 16 e 17 anos do Brasil. [internet] Brasília, DF: Secretaria-Geral da Presidência da República; 2015 [acesso em 2017 fev 5]. Disponível em: http://www.mapadaviolencia.org.br/pdf2015/ mapaViolencia2015.pdf.

6. Organização das Nações Unidas. Relatório sobre o estudo das Nações Unidas sobre a violência contra crianças. In: Pinheiro OS, organizador. [S.1.], 2006 [acesso em 2017 mar 13]. Disponível em: http://www. unviolencestudy.org.

7. Bardin, L. Análise de Conteúdo. 4. ed. Lisboa: Edições 70; 2008.

8. Brandao Neto W, Silva MAI, Aquino JM, et al. Violência sob o olhar de adolescentes: intervenção edu- cativa com Círculos de Cultura. Rev. Bras. Enferm. 2015; 68(4):617-625.

9. Ribeiro IMP. Vivências de situações de violências por crianças e adolescentes de 11 a 18 anos moradoras do Recanto das Emas, Distrito Federal. 2015 [tese]. [Brasília, DF]: Universidade de Brasília; 2015. 75 p.

10. Santana AFS. Representações Sociais de Estudantes do Ensino Fundamental da Rede Pública de Ensino acerca da Violência na Escola. Revista Inter Ação. 2012; 37(1):113-130.

11. Paixão GPN, Santos NJS, Matos LSL, et al. Violência escolar: percepções de adolescentes. Revista CUIDARTE. 2014; 5(2):717-22.

12. Silva PA, Lunardi VL, Lunardi GL, et al. Violência contra crianças e adolescentes: características dos casos notificados em um Centro de Referência do Sul do Brasil. Enfermería Global. 2017; 16(2):406-418.

13. Maia LLQGN, Araujo A, Santos Junior AS. O entendimento da violência escolar na percepção de adolescentes. Rev Med Minas Gerais. 2012; 22(2):166-173.

14. Silva LL, Coelho EBS, Caponi SN. Violência silenciosa: Violência psicológica como condição da violência física doméstica. Interface. 2007; 11(21):93-103.

15. Ralo JM. Violência doméstica entre adolescentes escolares no município de São Paulo. [dissertação]. [São Paulo]: Faculdade de Saúde Pública, Universidade de São Paulo; 2013.

16. Rates SMM, Melo EM, Mascarenhas MDM, et al. Violência infantil: uma análise das notificações compulsórias, Brasil 2011. Ciênc. Saúde Colet. 2015; 20(3):655665.

17. Borges LS, Alencar HM. Violências no cenário brasileiro: fatores de risco dos adolescentes perante uma realidade contemporânea. Journal of Human Growth and Development. 2015; 25(2):194-203. 
18. Gessner R, Fonseca RMGS, Oliveira RNG. Violência contra adolescentes: uma análise à luz das categorias gênero e geração. Rev. esc. enferm. USP. 2014; 48 (esp): 102-108.

19. Moura DR, Cruz ACN, Quevedo LA. Prevalência e características de escolares vítimas de bullying. J. Pediatr. 2011; 87(1):19-23.

20. Soares JSF, Lopes MJM. Biografias de gravidez e maternidade na adolescência em assentamentos rurais no Rio Grande do Sul. Rev. esc. enferm. USP, 2011; 45(4):802-810

21. Malta DC, Mascarenhas MDM, Bernal RTI, et al. Causas externas em adolescentes: atendimentos em serviços sentinelas de urgência e emergência nas Capitais Brasileiras - 2009. Ciênc. Saúde Colet. 2012; 17(9):2291-304.

22. Siqueira AC, Arpini DM, Savegnago SDO. Família e abuso sexual na perspectiva de adolescentes em situação de vulnerabilidade social. Aletheia, 2011; (34):109-122.

23. Pinto DMR, Araújo EM, Carvalho ESS, et al. Percepção de alunos/as sobre as causas da violência escolar. Adolesc Saúde. 2015; 12(3):83-87.

24. Melo EM. Podemos prevenir a violência. In: Melo EM, organizadora. Podemos prevenir a violência: teorias e práticas. Brasília, DF: Organização Pan-Americana da Saúde; 2010.

25. Melo EM, Melo MAM, Pimenta SMO, et al. A violência rompendo interações: as interações superando a violência. Revista Brasileira de Saúde Materno Infantil. 2007; 7(1):89-98.

Recebido em 21/11/ 2017

Aprovado em 03/10/2018

Conflito de interesses: inexistente

Suporte financeiro: não houve 